\title{
The Obesity Paradox in Patients with Severe Soft Tissue Infections
}

Arturo J. Rios-Diaz, MD ${ }^{1}$; Elissa Lin ${ }^{1}$; Katherine Williams, MPH ${ }^{1,2}$; Wei Jiang, MS ${ }^{1}$; Vihas Patel, MD ${ }^{1}$;

Naomi Shimizu, MD' David Metcalfe, LLB, MBChB ${ }^{3}$; Olubode A. Olufajo, MD, MPH; Zara Cooper,

MD, MSc ${ }^{1,2}$; Joaquim Havens, MD ${ }^{1,2} ;$ Ali Salim, MD ${ }^{1,2} ;$ Reza Askari, MD ${ }^{1,2}$

1. Center for Surgery and Public Health, Department of Surgery, Brigham and Women's Hospital. Harvard Medical School \& Harvard T. H. Chan School of Public Heath. Boston, MA

2. Trauma, Burn and Surgical Critical Care Division, Department of Surgery, Brigham and Women's Hospital. Harvard Medical School. Boston, MA

3. Nuffield Department of Orthopaedics, Rheumatology and Musculoskeletal Sciences, University of Oxford, Oxford, United Kingdom

Abstract presented at the Surgical Infection Society (SIS) 35th Annual Meeting in Westlake Village, CA, April 15-18, 2015.

\section{Corresponding author:}

Reza Askari, MD

Division of Trauma, Burn and Surgical Critical Care

Department of Surgery, Brigham and Women's Hospital,

75 Francis Street, Boston, MA 02115.

raskari@partners.org

Phone: +1 (617) 732-7736

Fax: 1+(617)566-9549

\section{Other author contact details:}

AJRD ariosdiaz@gmail.com; EL elissalin@college.harvard.edu; WJ wjiang3@ partners.org; VP vpate13@partners.org; KW kwilliams39@partners.org; NS nshimizu2@partners.org; DM dmetcalfe@ndorms.ox.ac.uk; OAO oolufajo@ partners.org; ZC zcooper@ partners.org; JH jhavens@ partners.org; AS salim1@partners.org; RA raskari@partners.org

Short title: Obesity Paradox in Severe Soft Tissue Infections

Conflicts of interest: The authors declare no conflicts of interest.

Funding: No specific funding was received with respect to this study.

Word count: 1,659

Keywords: Obesity paradox, severe soft tissue infections, nutritional support, mortality, acute surgery, NSTI, gas gangrene, Fournier's disease, necrotizing fasciitis 


\begin{abstract}
Background: The "obesity paradox" has been demonstrated in chronic diseases but not in acute surgery. We sought to determine whether obesity is associated with improved outcomes in patients with severe soft tissue infections (SSTIs).

Methods: The 2006-2010 Nationwide Inpatient Sample was used to identify adult patients with SSTIs. Patients were categorized into non-obese and obese (non-morbid [BMI 30-39.9] and morbid [BMI $>40]$ ). Logistic regression provided risk-adjusted association between obesity categories and in-hospital mortality.

Results: There were 2,868 records with SSTI weighted to represent 14,080 patients. Obese patients were less likely to die in hospital than non-obese patients (odds ratio $[\mathrm{OR}]=0.42,95 \%$ confidence interval $[\mathrm{CI}]$ 0.25-0.70; $\mathrm{p}=0.001)$. Subanalysis revealed a similar trend, with lower odds of mortality in non-morbid obesity $(\mathrm{OR}=0.46$, CI 0.23-0.91; $\mathrm{p}=0.025)$ and morbid obesity $(\mathrm{OR}=0.39, \mathrm{CI} 0.19-0.80 ; \mathrm{p}=0.011)$ groups. Conclusion: Obesity is independently associated with reduced in-hospital mortality in patients with SSTI regardless of the obesity classification. This suggests that the obesity paradox exists in this acute surgical population.
\end{abstract}




\section{Introduction}

Obesity is a growing public health issue that affects $35 \%$ of adults in the United States. ${ }^{1}$ It is known to be associated with a large range of diseases, including diabetes, dyslipidemia, hypertension, coronary artery disease, stroke, depression, sleep apnea, and a number of malignancies. ${ }^{2-5}$ It is also considered a risk factor for poor outcomes following surgical procedures. ${ }^{6}$ However, there is a growing body of evidence to support an "obesity paradox", which is a phenomenon that suggests a protective mortality effect of high body mass index (BMI) for some chronic diseases., ${ }^{2,6,7}$

The obesity paradox has been described in a number of acute ${ }^{8,9}$ and chronic ${ }^{10-12}$ disease populations, as well as following some interventional procedures ${ }^{2,6,13-16}$. However, there is little data to determine if this pattern is seen in surgical patients with severe skin and soft tissue infections (SSTI), including necrotizing soft tissue infections (NSTIs). The latter are rapidly spreading infections within the soft tissue compartment (dermis, subcutaneous tissue, superficial fascia, muscle or deep fascia) that are associated with necrotizing changes. ${ }^{17,18}$ Their management typically requires extensive surgical debridement as well resuscitation and intravenous antibiotics. ${ }^{18,19}$ As nutritional support plays an important role in patient recovery from SSTIs ${ }^{18,19}$, it has been suggested that individuals with higher BMIs have increased nutritional reserves conferring upon them a nutritional advantage that could improve hospital recovery. ${ }^{20}$ We conducted a small pilot study $(n=148)$ in a single academic center to examine outcomes in NSTI by nutrition feeding system and observed a trend towards reduced mortality in obese patients regardless of feeding technique. Although this study included a large number of patients with this relatively rare condition, the patients were all treated in one hospital and the results were not necessarily representative of the general population.

In order to examine the association between baseline BMI and hospital mortality in patients with SSTI, we examined hospital records from a nationally representative inpatient administrative database. We hypothesized that obesity will be associated with reduced mortality among these patients particularly in those with SSTI. 


\section{Methods}

\section{Data source}

We used the 2006-2010 National Inpatient Sample (NIS), which is the largest publicly accessible allpayer inpatient database in the United States. This nationally representative dataset includes all discharges from a $20 \%$ stratified sample of hospitals from across the United States. It is administered as part of the Healthcare Cost and Utilization Project (HCUP) by the Agency for Healthcare Research and Quality (AHRQ).

\section{Inclusion criteria}

Patients with SSTI were defined as those with a primary diagnosis International Classification of Diseases, Ninth Edition, Clinical Classification (ICD-9-CM) code pertaining to "gas gangrene" (040.0), "Fournier's disease" (608.83) or "necrotizing fasciitis" (728.86), and a ICD-9-CM procedure code corresponding to excisional or nonexcisional "debridement of wound, infection, or burn" (86.22 and 86.28 respectively). Patients aged $<18$ years old and those with any burn ICD-9-CM diagnosis code (940.0-949.5) were excluded. The remaining patients therefore had a soft tissue infection that was severe enough to require surgical debridement. ${ }^{17-19,21}$

\section{Variables and outcome measures}

Patients were categorized into non-obese or obese by using the AHRQ co-morbidity identifier for obesity. For bivariate and multivariable logistic regression analyses of mortality, obese patients were further stratified into obesity class 1 and 2 (BMI 30-30.9) and morbid obesity (BMI $\geq 40$ ); the latter identified by ICD-9-CM diagnosis code 278.01.

Extracted variables included age (categorized as $18-44,45-64,65-84$, and $\geq 84$ years), sex, race/ethnicity (non-Hispanic White, non-Hispanic Black, Hispanic, Asian/Pacific Islander, Native American, other and 
missing), estimated mean household income quartile based on ZIP code $(\$ 1-\$ 38,999 ; \$ 39,000$ - $\$ 47,999$; $\$ 48,000$ - $\$ 62,999 ; \$ 63,000$ or more), primary payer (private, Medicare, Medicaid, self-pay and other), Charlson Comorbidity Index (CCI; 0, 1-2, 3 and $\geq 4$ ), tube feeding (ICD-9-CM procedure codes 46.32, 46.39 and 96.6), total parenteral nutrition (ICD-9-CM procedure code 99.15), total hospital length-of-stay (coded as 0-3, 4-7 and >7 days), hospital size (NIS-defined large, medium and small bed size), rurality (defined by Core Based Statistical Area codes corresponding to non-metropolitan statistical areas), hospital region (Northeast, Midwest, South, West), hospital teaching status, and hospital affiliation to a multi-hospital system.

The primary outcome measure was in-hospital mortality, which was compared between obese vs. nonobese groups.

\section{Statistical analysis}

Categorical variables were compared using Pearson Chi-squared tests. Multivariable logistic regression was used to determine the independent association of obesity with mortality. Models were adjusted for all variables that were $p<0.5$ in bivariate analysis, which included patient- and hospital-level factors: age, race, gender, insurance, CCI, length-of-stay, hospital teaching status and hospital region.

NIS-provided population design weights were used to account for patient clustering within hospitals and to attain nationally weighted effects. Data analyses and management were performed using Stata 13 (College Station, TX, USA) and the threshold for statistical significance was set at $\mathrm{p}<0.05$ (two-tailed). The study protocol was approved by the Partners HealthCare Institutional Review Board. 


\section{Results}

Demographics, clinical and hospital characteristics

There were 2,868 records with SSTI weighted to represent 14,080 patients nationally, of which $75.7 \%$ were non-obese and $24.3 \%$ were obese. The mean age was 53.5 for non-obese (95\% Confidence Interval [CI]: 52.8-54.3) for non-obese and 50.2 (95\% CI: 49.2-51.2) for obese patients. Obese patients were more likely to be female, White, privately insured with less comorbidities associated (all $\mathrm{p}<0.001)$. Nonobese and obese groups were comparable in terms of income quartile, nutritional support (tube feeding and TPN), length-of-stay, and hospital characteristics (Table 1).

\section{Outcomes}

The overall mortality of our sample was $5.4 \%$. In unadjusted bivariate analyses, obesity was associated with lower in-hospital mortality for SSTI patients $(\mathrm{p}=0.004)$ (Table 2). After adjusting for all measured confounders, obese patients were less likely to die in hospital than their non-obese counterparts: obesity any-class (odds ratio [OR] 0.42, 95\% confidence interval [CI] 0.25-0.70; $\mathrm{p}=0.001$ ), obesity class 1 and 2 (OR 0.46, CI 0.23-0.91; $\mathrm{p}=0.025$ ) and morbid obesity (OR 0.39, CI 0.19-0.80; $\mathrm{p}=0.011$ ). 


\section{Discussion}

The obesity paradox was first described by in patients undergoing haemodialysis ${ }^{22}$ and has since been documented in those with peripheral arterial disease ${ }^{10}$, heart failure ${ }^{23}$, type 2 diabetes $^{2,12}$, coronary artery disease $^{7}$, and gastrointestinal malignancies ${ }^{14}$. The mechanism of this association remains unknown and possible explanations include an uncharacterized malnutrition-inflammation syndrome ${ }^{24}$, increased muscle strength ${ }^{25}$, and improved cardiorespiratory reserves in obese patients. However, the obesity paradox remains controversial and a number of possible explanations have been suggested. These include protein energy wasting in hemodialysis patients and cachexia as a poor prognostic sign in various chronic diseases $^{23}$. The comparative analyses of the present study reveal that the obesity paradox holds in the context of SSTI, as obesity is inversely associated with in-hospital mortality regardless of the obesity substratification.

There have been other explanations of the obesity paradox including attributing it to selection or lag-time biases. ${ }^{26}$ The selection bias argument states that most patients with a chronic disease (e.g. heart failure) develop comorbidities (e.g. alcoholic liver disease, coronary artery disease) first but that this step is omitted in obese patients, as obesity itself is a cause of heart failure. Obese heart failure patients are then the "healthiest" and would be expected to have better outcomes. The lag-time bias argument suggests that obese patients may be diagnosed more promptly (e.g. obesity aggravates breathless observed in heart failure) and so at earlier stage in their disease trajectory. ${ }^{27}$ These biases may partially account for the obesity paradox observed in peripheral arterial disease, coronary artery disease, heart failure, and type 2 diabetes. However, SSTI is an acute presentation and the obesity paradox in this population is not as readily explained by selection or lag-time biases. It is not immediately apparent that obesity itself should predispose to SSTI or result in earlier diagnosis. Nevertheless, it is feasible that deep wound infections requiring debridement are more common in obese patients. ${ }^{28,29}$ Non-obese patients might have other 
predisposing factors (e.g. poorly controlled diabetes, disseminated malignancy) that were not evident in the obese patients but associated with in-hospital mortality.

An alternative possibility specific to SSTI is that debridement of infected wounds could be a less invasive procedure in obese patients. For example, a non-obese patient undergoing extensive wound debridement may be left with open cavities and/or plastic surgical intervention to facilitate soft tissue coverage. An obese patient could undergo a much more extensive soft tissue debridement without compromising deep structures. Further work should aim to understand the cause(s) of the obesity paradox as this could lead to interventions (e.g. nutritional supplementation) to improve outcomes in the affected patient population.

The limitations of this study arise from our use of an administrative dataset. Although the CCI was included in our multivariable models, this cannot completely control for all co-morbidities. In particular, the use of ICD-9-CM codes within the NIS is insufficiently granular to identify subtle differences in comorbidity profiles between patients. For example, type 2 diabetes might be well controlled or poorly controlled, which may have implications both for development of SSTI and in-hospital mortality. We identified obese patients from a tag within the NIS. Since the documentation of obesity is dependent on whether the providers decided it was important enough to report it as a diagnosis during the admission, the extent to which this is obesity is captured is unknown. It is therefore possible that some obese patients were included within our non-obese group. However, this would be expected to underestimate any difference between the two groups rather than result in a strong negative association between obesity and in-hospital mortality. Other factors must be considered with the use of administrative data, such as the lack of physiologic data and the potential for misclassification, miscoding, and absent reporting of pertinent events not detectable without individual chart review. 
In summary, the obesity paradox remains controversial but has been described across a range of chronic disease populations. To the best of our knowledge, this study represents the first time that the obesity paradox has been described in an acute surgical population. This finding cannot readily be explained by the lag-time bias suggested for the obesity paradox in chronic disease. The persistence of such a strongly apparent protective effect outside the chronic disease setting lends weight to proponents of the obesity paradox as a genuine clinical entity. 


\section{References}

1. Ogden CL, Carroll MD, Kit BK, Flegal KM. PRevalence of childhood and adult obesity in the united states, 2011-2012. JAMA. 2014/02/26/ 2014;311(8):806-814.

2. Hainer V, Aldhoon-Hainerová I. Obesity Paradox Does Exist. Dia Care. 2013/08/01/ 2013;36(Supplement 2):S276-S281.

3. Ahima RS, Lazar MA. The Health Risk of Obesity-Better Metrics Imperative. Science. 2013/08/23/ 2013;341(6148):856-858.

4. McMichael AJ. Food, nutrition, physical activity and cancer prevention. Authoritative report from World Cancer Research Fund provides global update. Public Health Nutr. 2008/07// 2008;11(7):762-763.

5. Zogg CK, Mungo B, Lidor AO, et al. Influence of body mass index on outcomes after major resection for cancer. Surgery. Aug 2015;158(2):472-485.

6. Mullen JT, Moorman DW, Davenport DL. The Obesity Paradox: Body Mass Index and Outcomes in Patients Undergoing Nonbariatric General Surgery. Annals of Surgery. 2009/07// 2009;250(1):166-172.

7. Gruberg L, Weissman NJ, Waksman R, et al. The impact of obesity on the short-term and longterm outcomes after percutaneous coronary intervention: the obesity paradox? J. Am. Coll. Cardiol. 2002/02/20/ 2002;39(4):578-584.

8. Barba R, Zapatero A, Losa JE, et al. Body mass index and mortality in patients with acute venous thromboembolism: findings from the RIETE registry. J. Thromb. Haemost. 2008/04// 2008;6(4):595-600.

9. Hutagalung R, Marques J, Kobylka K, et al. The obesity paradox in surgical intensive care unit patients. Intensive Care Med. 2011/11// 2011;37(11):1793-1799. 
10. Galal W, van Gestel YRBM, Hoeks SE, et al. The obesity paradox in patients with peripheral arterial disease. Chest. 2008/11// 2008;134(5):925-930.

11. Barba R, Bisbe J, Pedrajas JNA, et al. Body mass index and outcome in patients with coronary, cerebrovascular, or peripheral artery disease: findings from the FRENA registry. European Journal of Cardiovascular Prevention \& Rehabilitation. 2009/08/01/ 2009;16(4):457-463.

12. Doehner W, Erdmann E, Cairns R, et al. Inverse relation of body weight and weight change with mortality and morbidity in patients with type 2 diabetes and cardiovascular co-morbidity: an analysis of the PROactive study population. Int. J. Cardiol. 2012/12/15/ 2012;162(1):20-26.

13. Sohn M-W, Budiman-Mak E, Oh EH, et al. Obesity paradox in amputation risk among nonelderly diabetic men. Obesity (Silver Spring). 2012/02// 2012;20(2):460-462.

14. Yasunaga H, Horiguchi H, Matsuda S, Fushimi K, Hashimoto H, Ayanian JZ. Body mass index and outcomes following gastrointestinal cancer surgery in Japan. Br J Surg. 2013/09// 2013;100(10):1335-1343.

15. Paul S, Andrews W, Osakwe NC, et al. Perioperative Outcomes after Lung Resection in Obese Patients. Thorac Cardiovasc Surg. 2014/07/28/ 2014.

16. Aldhoon B, Wichterle D, Peichl P, Čihák R, Kautzner J. Complications of catheter ablation for atrial fibrillation in a high-volume centre with the use of intracardiac echocardiography. Europace. 2013/01// 2013;15(1):24-32.

17. Howell GM, Rosengart MR. Necrotizing soft tissue infections. Surg Infect (Larchmt). 2011/06// 2011;12(3):185-190.

18. Goldstein EJC, Anaya DA, Dellinger EP. Necrotizing Soft-Tissue Infection: Diagnosis and Management. Clin Infect Dis. 2007/03/01/ 2007;44(5):705-710.

19. Phan HH, Cocanour CSMD. Necrotizing soft tissue infections in the intensive care unit. [Miscellaneous Article]. Critical Care Medicine. 2010/09//undefined 2010;38(9). 
20. Utzolino S, Ditzel CM, Baier PK, Hopt UT, Kaffarnik MF. The obesity paradox in surgical intensive care patients with peritonitis. Journal of critical care. Oct 2014;29(5):887 e881-885.

21. Hussein QA, Anaya DA. Necrotizing soft tissue infections. Crit Care Clin. 2013/10// 2013;29(4):795-806.

22. Fleischmann E, Teal N, Dudley J, May W, Bower JD, Salahudeen AK. Influence of excess weight on mortality and hospital stay in 1346 hemodialysis patients. Kidney international. Apr 1999;55(4):1560-1567.

23. Habbu A, Lakkis NM, Dokainish H. The obesity paradox: fact or fiction? The American journal of cardiology. Oct 1 2006;98(7):944-948.

24. Kalantar-Zadeh K, Block G, Horwich T, Fonarow GC. Reverse epidemiology of conventional cardiovascular risk factors in patients with chronic heart failure. J Am Coll Cardiol. Apr 21 2004;43(8):1439-1444.

25. Wannamethee SG, Shaper AG, Whincup PH, Lennon L, Papacosta O, Sattar N. The obesity paradox in men with coronary heart disease and heart failure: the role of muscle mass and leptin. Int J Cardiol. Jan 15 2014;171(1):49-55.

26. Lajous M, Banack HR, Kaufman JS, Hernan MA. Should patients with chronic disease be told to gain weight? The obesity paradox and selection bias. The American journal of medicine. Apr 2015;128(4):334-336.

27. Rayner JJ, Neubauer S, Rider OJ. The paradox of obesity cardiomyopathy and the potential for weight loss as a therapy. Obesity reviews : an official journal of the International Association for the Study of Obesity. Aug 2015;16(8):679-690.

28. Pitan O, Williams M, Obirieze A, et al. Lower extremity arterial reconstruction in obese patients. American journal of surgery. Apr 2015;209(4):640-644. 
29. Ayres-de-Campos D. Obesity and the challenges of caesarean delivery: prevention and management of wound complications. Best practice \& research. Clinical obstetrics \& gynaecology. Apr 2015;29(3):406-414. 
Table 1. Demographic, clinical case-mix, and hospital-level (weighted percentages) of patients with SSTI undergoing surgical debridement by type of nutritional support

\begin{tabular}{|c|c|c|c|}
\hline Weighted $\mathrm{N},(\%)$ & $\begin{array}{l}\text { Non-Obese } \\
10658(75.7) \\
\end{array}$ & $\begin{array}{c}\text { Obese } \\
3423(24.3) \\
\end{array}$ & $p$ \\
\hline \multicolumn{4}{|l|}{ Patient Characteristics } \\
\hline Age $(\%)$ & & & $<0.001$ \\
\hline $18-44$ & $(25.2)$ & $(30.4)$ & \\
\hline $45-64$ & $(53.7)$ & $(57.5)$ & \\
\hline $65-84$ & (19.1) & $(12.0)$ & \\
\hline $85+$ & $(2.0)$ & $(0.1)$ & \\
\hline Gender $(\%)$ & & & $<0.001$ \\
\hline Male & $(67.1)$ & $(48.3)$ & \\
\hline Female & $(32.9)$ & $(51.7)$ & \\
\hline Race/Ethnicity (\%) & & & $<0.001$ \\
\hline White & $(47.2)$ & $(57.4)$ & \\
\hline Black & $(14.7)$ & (12.9) & \\
\hline Hispanic & (11.7) & $(6.2)$ & \\
\hline Asian/Pa & $(1.5)$ & (1.1) & \\
\hline Native A & $(0.9)$ & $(0.8)$ & \\
\hline Other & $(2.7)$ & $(1.7)$ & \\
\hline Missing & $(21.4)$ & (19.8) & \\
\hline Payer $(\%)$ & & & $<0.001$ \\
\hline Private, including HMO & $(28.7)$ & $(40.2)$ & \\
\hline Medicare & $(30.4)$ & $(25.0)$ & \\
\hline Medicaid & (17.9) & (18.3) & \\
\hline Self-pay & (13.1) & (11.6) & \\
\hline Other & $(9.9)$ & $(4.9)$ & \\
\hline Income Quartile (\%) & & & 0.583 \\
\hline $1 \mathrm{st}$ & $(36.9)$ & $(34.6)$ & \\
\hline 2nd & $(27.2)$ & $(28.7)$ & \\
\hline $3 \mathrm{rd}$ & $(20.7)$ & $(22.4)$ & \\
\hline 4th & $(15.2)$ & $(14.3)$ & \\
\hline Charlson Comorbidity Index score (\%) & & & $<0.001$ \\
\hline 0 & $(32.4)$ & $(16.5)$ & \\
\hline 1 & $(30.3)$ & $(39.6)$ & \\
\hline 2 & $(17.4)$ & $(20.6)$ & \\
\hline 3 & $(9.0)$ & (11.3) & \\
\hline$>4$ & $(11.0)$ & (11.9) & \\
\hline Tube feeding $(\%)$ & $(2.4)$ & $(2.4)$ & 0.978 \\
\hline Total parenteral nutrition (\%) & $(2.5)$ & $(3.0)$ & 0.521 \\
\hline Length of stay (\%) & & & 0.169 \\
\hline $0-3$ days & $(7.0)$ & $(4.9)$ & \\
\hline 3-7 days & $(18.0)$ & (17.4) & \\
\hline$>7$ days & $(75.1)$ & $(77.6)$ & \\
\hline \multicolumn{4}{|l|}{ Hospital characteristics } \\
\hline Bed size $(\%)^{*}$ & & & 0.578 \\
\hline Small & $(10.7)$ & (11.4) & \\
\hline Medium & $(23.2)$ & $(25.1)$ & \\
\hline Large & $(66.0)$ & $(63.5)$ & \\
\hline Rural location (\%) & $(9.4)$ & $(9.7)$ & 0.814 \\
\hline Region $(\%)$ & & & 0.209 \\
\hline Northeast & $(14.1)$ & $(12.9)$ & \\
\hline Midwest & $(21.7)$ & $(25.5)$ & \\
\hline South & $(39.9)$ & $(41.0)$ & \\
\hline West & $(24.3)$ & $(20.7)$ & \\
\hline Teaching status $(\%)$ & $(57.6)$ & $(52.9)$ & 0.071 \\
\hline Member multihospital system(\%) & $(63.6)$ & $(65.4)$ & 0.541 \\
\hline
\end{tabular}


Table 2. Mortality of severe skin and soft tissue infection cases by obesity classification.

\begin{tabular}{|c|c|c|c|c|}
\hline & $\begin{array}{c}\text { Non-Obese } \\
(\text { BMI<30) }\end{array}$ & $\begin{array}{c}\text { Obese (BMI 30- } \\
\text { 39.9) }\end{array}$ & $\begin{array}{c}\text { Morbid-Obese } \\
(\text { BMI } \geq 40)\end{array}$ & $p$ \\
\hline $\begin{array}{l}\text { Weighted N, } \\
(\%)\end{array}$ & $10658(75.7)$ & $1541(10.9)$ & $1882(13.4)$ & \\
\hline \multirow[t]{2}{*}{ Mortality (\%) } & $(6.2)$ & (3.2) & (2.6) & 0.004 \\
\hline & $\begin{array}{c}\text { Non-Obese } \\
(\text { BMI<30) }\end{array}$ & $\begin{array}{c}\text { Obese (BMI 30- } \\
\text { 39.9) }\end{array}$ & $\begin{array}{c}\text { Morbid-Obese } \\
(\text { BMI } \geq 40)\end{array}$ & $p$ \\
\hline $\begin{array}{l}\text { Weighted } \mathrm{N}, \\
(\%)\end{array}$ & $10658(75.7)$ & $1541(10.9)$ & $1882(13.4)$ & \\
\hline Mortality (\%) & $(6.2)$ & $(3.2)$ & $(2.6)$ & 0.004 \\
\hline $\begin{array}{l}\begin{array}{l}\text { Obesity } \\
\text { classification }\end{array} \\
\end{array}$ & $\begin{array}{c}\begin{array}{c}\text { Non-Obese } \\
(\text { BMI<30) }\end{array} \\
\end{array}$ & $\begin{array}{c}\text { Obesity any class } \\
(\text { BMI } \geq 30)\end{array}$ & & $p$ \\
\hline Weighted $\mathrm{N},(\%)$ & $10658(75.7)$ & $3418(24.7)$ & & \\
\hline \multirow[t]{2}{*}{ Mortality (\%) } & $(6.2)$ & $(0.3)$ & & $<0.001$ \\
\hline & $\begin{array}{c}\text { Non-Obese } \\
(\mathrm{BMI}<30)\end{array}$ & $\begin{array}{c}\text { Obesity class } 1 \& 2 \\
(\text { BMI 30-39.9) } \\
\end{array}$ & $\begin{array}{c}\text { Morbid-Obese } \\
(\mathrm{BMI} \geq 40)\end{array}$ & $p$ \\
\hline Weighted $\mathrm{N},(\%)$ & $10658(75.7)$ & $1541(10.9)$ & $1882(13.4)$ & \\
\hline Mortality (\%) & $(6.2)$ & $(3.2)$ & $(2.6)$ & 0.004 \\
\hline
\end{tabular}

Figure 1. Forest plot of risk-adjusted mortality among severe skin and soft tissue infection cases by obesity classification.

Footnote: Non-obesity $\left(\mathrm{BMI}<30 \mathrm{~kg} / \mathrm{m}^{2}\right)$; Obesity, any type $\left(\mathrm{BMI} \geq 30 \mathrm{~kg} / \mathrm{m}^{2}\right)$; Non-morbid Obesity $\left(\mathrm{BMI} 30-39.9 \mathrm{~kg} / \mathrm{m}^{2}\right)$; Morbid-obesity $\left(\mathrm{BMI} \geq 40 \mathrm{~kg} / \mathrm{m}^{2}\right)$. Models were adjusted for age, gender, race, insurance, Charlson Comorbidity Index, length-of-stay and hospital characteristics. 